\title{
Tympani Thermometer Design Using Passive Infrared Sensor
}

\author{
Nur Hudha Wijaya ${ }^{1}$, Zanella Oktavihandani ${ }^{2}$, Kunal Kunal $^{3}$, Elsayed T. Helmy ${ }^{4}$, Phong Thanh Nguyen ${ }^{5}$ \\ ${ }^{1,2}$ Department of Electrical Engineering, Universitas Muhammadiyah Yogyakarta, Yogyakarta, Indonesia \\ ${ }^{3}$ School of Information, Communication \& Technology, Indraprastha University, Delhi, India \\ ${ }^{4}$ National Institute of oceanography and fisheries, Alexandria \\ ${ }^{5}$ Director, Department of Project Management, Ho Chi MinhCity Open University, Vietnam \\ Email: nurhudhawijaya@umy.ac.id,oktavihandanizanella.2015@vokasi.umy.ac.id., Kunal.karn007@gmail.com, \\ stalaat41@gmail.com, phong.nt@ou.edu.vn
}

\begin{abstract}
Measuring body temperature depends on the type of thermometer and measured body area. A thermometer placed on the tympanic membrane is considered ideal because the tympanic membrane and hypothalamus have arterial blood supply originating from the carotid artery (neck). Therefore, it is considered directly close to the core temperature. The Tympani Thermometer with external storage can facilitate the doctor's performance in diagnosing patients. This tool is designed using the MLX90614 sensor as a passive infrared sensor that can receive infrared energy from the tympanic membrane. The study aims to design a tympani thermometer. It compared the measurement results of the designed tool with ear thermometers that have been calibrated to get the error value. Based on the results, this prototype works well and has an error of $0.7^{\circ} \mathrm{C}$ in the left ear and an error of $0.24^{\circ} \mathrm{C}$ in the right ear.
\end{abstract} tympani

Keywords - body temperature, infrared sensor, thermometer,

\section{INTRODUCTION}

Temperature measurement is one of the oldest known diagnostic methods and remains an important indicator in diagnosing disease, both in daily life and in medical care. To measure body temperature depends on the type of thermometer and body area used for measurement. Body temperature in humans varies greatly depending on the location where the reading is done. Thermometers in the tympanic membrane using infrared are considered ideal because the tympanic membrane and hypothalamus have arterial blood supply originating from the carotid artery (neck). Therefore, the tympanic membrane is considered directly close to the core temperature.

Humans can also be called homoiothermic creatures, meaning that the body temperature in humans will be stable even though the ambient temperature has fluctuated far above or below body temperature, in this case, the skin plays an important role in maintaining body temperature, in the skin there is a network of blood vessels and sweat glands that are controlled by nervous system. In addition, there are receptors among which are thermoreceptors, which are receptors in the body that are very sensitive to changes in temperature.

Several previous researchers have conducted research on temperature measurement and temperature control. Hsiao conducted research on microsensor printed to detect temperature and humidity simultaneously. Temperature and humidity sensors with dimensions of less than $1 \times 1 \mathrm{~mm} 2$ were printed together on a flexible polyimide substrate to create a mini-sensing circuit. Changes in humidity (RH 35\%-95\%) were detected by the changes in the printed capacitance of thin film of Nafion, while temperature variations $\left(15^{\circ} \mathrm{C}-80\right.$ $\left.{ }^{\circ} \mathrm{C}\right)$ were detected by the changes in the resistance of thin films of printed $\mathrm{NiO}$ [1]. Implementation of FPGA-based real-time temperature measurement via spectroscopy absorption of laser tunable diode was studied by $\mathrm{Xu}$. The system used real-time temperature measurements using (FPGA) through a diode laser absorption spectroscopy to measure the average temperature along the laser path. The Spectroscopic Modulation Wavelength (SMW) method was applied to realize temperature measurements [2].

Roy conducted research on automatic room light and fan controllers based on microcontrollers. The fan speed changed according to temperature. The room door was equipped with a laser detector to identify when someone was entering the room. The fan and lights would turn on [3]. microcontroller based monitoring and control of environmental conditions in agriculture was examined by Kalezhi. Poultry production was influenced by temperature and lighting variations, which, if not monitored and controlled, would affect production. The system combined the Atmel 32bit ARM microcontroller and sensors to monitor and control temperature and light. The sensor readings processed by the microcontroller program were then analyzed by the MATLAB server program, which in turn communicated with the server embedded in the wireless energy gateway [4]. A solar panel monitoring system using a microcontroller-based smartphone was researched by Gusa. The system consisted of three sensors namely voltage sensor, current sensor, and temperature sensor, an ATMEGA2560 Arduino type microcontroller, a Wi-Fi and a smartphone. The data from the three sensors were processed by the microcontroller and transmitted using the Wi-Fi module to be monitored by the smartphone [5].

The design of the temperature and humidity control system of the server room using fuzzy logic based on microcontrollers was examined by Purwanto. The system consisted of a temperature sensor, a humidity sensor, and a Wemos microcontroller [6]. A multi-parameter water quality monitor for grouper cultivation was examined by Defe. The system consisted of a temperature sensor, a $\mathrm{pH}$ sensor, an 
electrical conductivity sensor, a dissolved oxygen sensor, an Arduino Mega 2560 microcontroller, an LCD, and an alarm. The data from many sensors were processed by the microcontroller then displayed on the LCD and sounded the alarm when the value is less than specified [7]. The design of the micro-automatic weather station for a modern electricity network based on STM32 was examined by Li. The system consisted of a STM32F103VETb type microcontroller, five sensors namely a temperature sensor using DS18B20, a humidity sensor using DHT11, a GPS sensor, a light sensor using a BH1750FVI, and a transmission system using GPRS [8].

The 3-D novel embedded module for measuring displacement in a metal structure was examined by Rojas. The system consisted of four sensors namely inductive sensor for detecting metals, nine sensors from IMU, a temperature sensor and a humidity sensor, and a microcontroller with radio frequencies [9]. The sensor error classification based on vector engine support and time-domain statistical features was examined by Jan. The system consisted of a temperature sensor using TC1047/TC1047A Arduino Uno type microcontroller, and a computer. The data from the temperature sensor is read by the Arduino Uno by using an ADC port. The data were transmitted to the computer and then processed and displayed with Matlab [10]. An automatic temperature and humidity control system using Fuzzy Logic algorithm for mushroom nursery was investigated by Kaewwiset. The system consisted of air humidity sensor and temperature sensor using DHT11, an Arduino UNO R3 microcontroller, a fan, a lamp, and a mist sprayer. The data from the sensor were processed using the fuzzy logic method [11]. The design and implementation of wireless systems using microcontroller and microcomputer with applications to drive the acquisition system were examined by Fekhar. The system consisted of a PIC PIC18F458 microcontroller, an AD590 type temperature sensor, a Samson-3804 pressure sensor, and a GLCD viewer. The temperature and pressure sensor data were processed by the computer [12].

A robotic automatic control system design for oil temperature hydraulic system coal sample taking was examined by Li. The system consisted of a DS18B20temperature sensor, an STM32 F103RCT6 type microcontroller, and a computer. The data from the sensor were read by the STM32 microcontroller and then processed and displayed by the computer [13]. The design of a peat fire detection system with woody peat type using the characteristics of its heat was examined by Amri. The system consisted of an LM35 temperature sensor, an ATMEGA8 microcontroller, and an LCD. The data from the LM35 sensor were processed by the ATMEGA8 microcontroller and then displayed on the LCD [14]. The development of the humanmachine interface using the Synergy-S7 Renesas microcontroller for industrial data monitoring was researched by Kavitha. The system consisted of an Arm Cortex M4 core microcontroller, a TFT-LCD viewer, and two sensors namely Light sensor and temperature sensor. The data from the two sensors were processed by using the Arm Cortex M4 core and then displayed on the LCD [15]. The robotic system for temperature recording of the environment by direct tracking was examined by Naik. The system consisted a temperature sensor, a camera sensor, an AT89S51 microcontroller, a DC motor, and a DC motor driver. The data from the temperature sensor were processed by the microcontroller, and then the data were used to drive the DC motor [16]. The Digital microcontroller-based gauge with warning systems using GSM was examined by Bharathkumar. The system consisted of an LM35 temperature sensor, a DHT11humidity sensor, a PIC microcontroller, a GSM module, and an LCD. The sensor data were processed by the microcontroller then transmitted using SMS with the GSM module and displayed on the LCD [17].

Designing and making an efficient digital type thermometer that can be used safely and accurately in the world of health and the general public is the aim of the research. The advantage of the tool is that it can detect the temperature of an object (ear canal) where the ear canal is connected directly to the central regulator of body temperature (hypothalamus) which means that the ear is the actual temperature of the body in seconds with the output of a unit of measured values in the form of numbers. Previous research has been carried out related to body temperature measurements on the forehead, where the tool is still less effective because often the temperature reading on the forehead is affected by the room temperature due to its placement there is a distance between the sensor and the object so that it encourages the writer to design and make a human body temperature gauge on the burrow ear to measure the actual temperature found in the human body based on Atmega 328.

\section{METHOD}

The design of the infrared temperature design [18]-[24] system using an infrared passive sensor is shown in the block diagram of Figure 1. From Figure 1 it appears that the system consists of a Tympani membrane, an MLX90614 Sensor, a microcontroller, and an LCD.

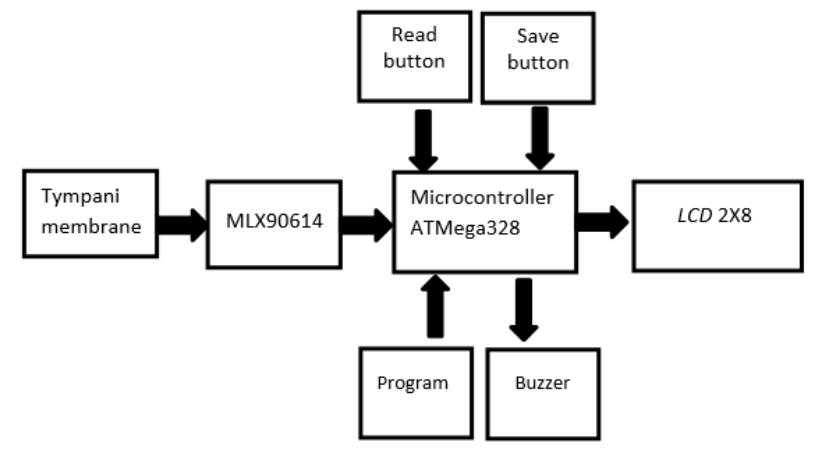

Fig. 1. System block diagram

The scan button is a button used to detect the MLX90614 sensor [22], [25]-[28]. The save button functions as a button to save data on the SD card. The program works as a data processor to be sent by IC AtMega 328 microcontroller. The microcontroller [19], [29]-[32] is the brain to process analog data in the form of digital data that will be displayed on the LCD. A buzzer is used to give a sign that the tool starts detecting objects. The battery functions as a voltage supply to the entire system. The LCD used is 2x8. The MLX90614 sensor is used to measure temperature by utilizing infrared wave radiation. It is specially designed to detect infrared 
radiation so that it can calibrate infrared radiation energy to a temperature scale. The tympani membrane detects body temperatures to help doctors diagnose illnesses in patients.

\section{A. System workflow}

The design of the tympanic temperature flowchart design system is shown in the block diagram Figure 2. From the Figure, it appears that the system must initialize all hardware consisting of LCD, sensors, and buzzers.

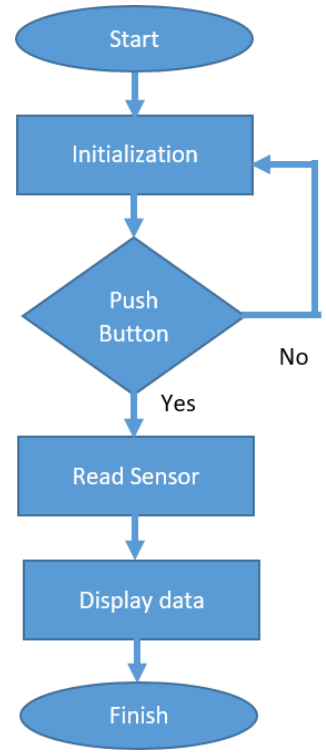

Fig. 2. System work flow chart

The start is the beginning of the program. Initialization is the preparation in the form of LCD initialization. MLX90614 initialization is preparation when the sensor starts detecting. Press Scan is a process when the sensor starts working to detect objects in the ear canal. A buzzer functioned to give a sign that the tool began to detect. The processing time of taking temperature on an object was 8 seconds. The detected temperature will be displayed on the LCD. A memory button is used to store data on the SD card. After the data have been stored on the SD card, the process is complete.

\section{RESULT AND DISCUSSION}

\section{A. Measurement Test}

The test was performed by comparing the thermometer module with IT-903 digital thermometer. The data were collected at three measurement points namely right ear, left ear and forehead. 10 times and 40 times measurements on the ear and forehead were performed to look for the bias between the ear and forehead.

The right and the left ears of the patient's body were examined to determine the level of error in the device by making comparisons with IT-903 Digital Thermometer. The respondents were 30 . Table 1 presents the Error measurement results.

The average temperature of the instrument module of the 30 respondents was $36.47{ }^{\circ} \mathrm{C}$ with an error of $0.6 \%$ on the right ear and $36.36{ }^{\circ} \mathrm{C}$ with an error of $0.7 \%$ on left ear with a difference in the comparator (IT-903) of $0.24{ }^{\circ} \mathrm{C}$ in the right ear and $0.27{ }^{\circ} \mathrm{C}$ in the left ear. It can be concluded that the instrument is suitable for use with a deviation tolerance of 1.5 ${ }^{\circ} \mathrm{C}$.

TABLE I. ERROR MEASUREMENT RESULTS

\begin{tabular}{|c|c|c|}
\hline Deviation & Right ear $0.24^{\circ} \mathrm{C}$ & Left ear $0.27^{\circ} \mathrm{C}$ \\
\hline Error (\%) & $\mathbf{0 . 6 \%}$ & $\mathbf{0 . 7 \%}$ \\
\hline $\begin{array}{c}\text { Standart } \\
\text { deviation }\end{array}$ & $\mathbf{0 . 3}$ & $\mathbf{0 . 2}$ \\
\hline $\boldsymbol{U}_{\boldsymbol{A}}$ & $\mathbf{0 . 0 9}$ & $\mathbf{0 . 0 8}$ \\
\hline
\end{tabular}

\section{B. System Test}

In the system test, the ears and forehead of four respondents were examined to determine e the level of bias in the instrument by making comparisons with IT-903 Digital Thermometer.

The average bias of the instrument module obtained from the 1 st respondent was $0.54{ }^{\circ} \mathrm{C}$ and the bias on IT-903 was 0.84 with an error percentage of 0.4 on the forehead and 0.3 on the ear. The high error on the forehead was caused by an incorrect position and the influence of ambient temperature. From the 2nd respondent, it was $0.07{ }^{\circ} \mathrm{C}$ and the bias on IT903 was 0.3 with an error percentage of 0.62 on the forehead and 0.67 on the ear. The high error in the ear is caused by incorrect positioning of the sensor.

The average bias of the module obtained from the $3 \mathrm{rd}$ respondent was $0.41{ }^{\circ} \mathrm{C}$ and the bias of IT-903 was 0.07 with an error percentage of 0.54 on the forehead and 0.3 on the ear. The high error on the forehead was caused by the incorrect position and the influence of the ambient temperature. From the 4th respondent, it was $0.11^{\circ} \mathrm{C}$ and the bias of IT-903 was 0.1 with an error percentage of 0.6 on the forehead and 0.5 on the ear. The high error on the forehead was caused by incorrect positioning and the influence of ambient temperature.

In the thermometer measurements on the ears and forehead, the highest error is $0.67 \%$ with $0.84{ }^{\circ} \mathrm{C}$ bias. This figure is in accordance with the theory conducted by several studies that the bias between ear and forehead is $0,3-0.6{ }^{\circ} \mathrm{C}$ lower than ear temperature because the ear is closer to the core temperature in the hypothalamus. The ear is connected to the hypothalamus by the carotid artery located in the neck.

\section{CONCLUSION}

In the thermometer measurement, the average temperature of 30 respondents on the instrument module is $36.47^{\circ} \mathrm{C}$ with an error of $0.6 \%$ in the right ear and $36.36^{\circ} \mathrm{C}$ with an error of $0.7 \%$ in the left ear with a difference in the comparator (IT903) of $0.24{ }^{\circ} \mathrm{C}$ in the right ear and $0.27{ }^{\circ} \mathrm{C}$ in the left ear. It can be concluded that the device is suitable for use with a tolerance of deviation of $1.5{ }^{\circ} \mathrm{C}$. In the thermometer measurements the ears and forehead, the highest error is $0.67 \%$ with the bias of the ear and forehead thermometer is $0.84{ }^{\circ} \mathrm{C}$. This figure is according to the theory conducted by several studies that the bias between ear and forehead is 0,3 $0.6{ }^{\circ} \mathrm{C}$ lower than ear temperature. It is because the ear is closer to the core temperature in the hypothalamus. The ears 
are connected to the hypothalamus by the carotid artery located in the neck..

\section{REFERENCES}

[1] F. Hsiao and Y. Liao, "Printed Micro-Sensors for Simultaneous Temperature and Humidity Detection," IEEE Sens. J., vol. 18, no. 16, pp. 6788-6793, Aug. 2018.

[2] L. Xu, R. Xue, Y. Li, H. Zhang, and Z. Cao, "FPGA-Based RealTime Implementation of Temperature Measurement via Tunable Diode Laser Absorption Spectroscopy,” IEEE Sens. J., vol. 18, no. 7, pp. 2751-2758, Apr. 2018.

[3] P. Roy, J. Saha, N. Dutta, and S. Chandra, "Microcontroller based automated room light and fan controller," in 2018 Emerging Trends in Electronic Devices and Computational Techniques (EDCT), 2018, pp. 1-4.

[4] J. Kalezhi, J. Mbale, and L. Ndovi, "Microcontroller-Based Monitoring and Controlling of Environmental Conditions in Farming," in 2018 IEEE PES/IAS PowerAfrica, 2018, pp. 284-288.

[5] R. F. Gusa, W. Sunanda, I. Dinata, and T. P. Handayani, "Monitoring System for Solar Panel Using Smartphone Based on Microcontroller," in 2018 2nd International Conference on Green Energy and Applications (ICGEA), 2018, pp. 79-82.

[6] F. H. Purwanto, E. Utami, and E. Pramono, "Design of server room temperature and humidity control system using fuzzy logic based on microcontroller," in 2018 International Conference on Information and Communications Technology (ICOIACT), 2018, vol. 2018Janua, pp. 390-395.

[7] G. A. Defe and A. Z. C. Antonio, "Multi-parameter Water Quality Monitoring Device for Grouper Aquaculture," in 2018 IEEE 10th International Conference on Humanoid, Nanotechnology, Information Technology,Communication and Control, Environment and Management (HNICEM), 2018, no. December, pp. 1-5.

[8] H. Li, M. K. Ochani, H. Zhang, and L. Zhang, "Design of microautomatic weather station for modern power grid based on STM32," J. Eng., vol. 2017, no. 13, pp. 1629-1634, Jan. 2017.

[9] D. Rojas and J. Barrett, "A Novel 3-D Embedded Module for Displacement Measurement in Metal Structures," IEEE Trans. Components, Packag. Manuf. Technol., vol. 7, no. 11, pp. 17651773, Nov. 2017.

[10] S. U. Jan, Y.-D. Lee, J. Shin, and I. Koo, "Sensor Fault Classification Based on Support Vector Machine and Statistical Time-Domain Features,” IEEE Access, vol. 5, pp. 8682-8690, 2017.

[11] T. Kaewwiset and P. Yodkhad, "Automatic temperature and humidity control system by using Fuzzy Logic algorithm for mushroom nursery," in 2017 International Conference on Digital Arts, Media and Technology (ICDAMT), 2017, pp. 396-399.

[12] H. Fekhar and H. Habbi, "Design and implementation of wireless system by using microcontrollers and microcomputer with application to drive acquisition system," in 2017 International Conference on Control, Automation and Diagnosis (ICCAD), 2017, pp. 070-075.

[13] H. Li, H. Xu, J. Wang, X. Fu, and Z. Bai, "Design of Automatic Control System of Coal Sampling Robot Hydraulic System Oil Temperature," in 2017 9th International Conference on Intelligent Human-Machine Systems and Cybernetics (IHMSC), 2017, vol. 1, pp. $38-42$.

[14] R. Amri, N. L. Marpaung, E. Ervianto, and Nurhalim, "Design of firing detector system by peat land with woody peat types using it's heat characteristics," in 2017 5th International Conference on Instrumentation, Control, and Automation (ICA), 2017, pp. 130134.

[15] S. Kavitha and H. Kalpana, "Development of human machine interface using renesas Synergy-S7 microcontroller for industrial data monitoring," in 2017 2nd IEEE International Conference on Recent Trends in Electronics, Information \& Communication Technology (RTEICT), 2017, vol. 2018-Janua, pp. 1080-1083.
[16] G. R. Naik, P. Mahesh, B. Mohan, and V. R. Mahathi, "Robotic system for recording ambience temperature with live tracking," in 2017 International Conference on Intelligent Computing and Control Systems (ICICCS), 14613BC, pp. 46-50.

[17] Bharathkumar V., Irshad SM, Gowtham S., and R. Geethamani, "Microcontroller based digital meter with alert system using GSM," in 2017 11th International Conference on Intelligent Systems and Control (ISCO), 2017, pp. 444-448.

[18] A. Ghahramani, G. Castro, S. A. Karvigh, and B. Becerik-Gerber, "Towards unsupervised learning of thermal comfort using infrared thermography," Appl. Energy, vol. 211, no. October 2017, pp. 4149, Feb. 2018.

[19] C. Lee and Y.-J. Wang, "Psychrometer based on a contactless infrared thermometer with a predictive model for water evaporation,” Biosyst. Eng., vol. 160, no. 70, pp. 84-94, Aug. 2017.

[20] D. Li, C. C. Menassa, and V. R. Kamat, "Non-intrusive interpretation of human thermal comfort through analysis of facial infrared thermography," Energy Build., vol. 176, pp. 246-261, Oct. 2018.

[21] H. G. Jones, P. A. Hutchinson, T. May, H. Jamali, and D. M. Deery, "A practical method using a network of fixed infrared sensors for estimating crop canopy conductance and evaporation rate," Biosyst. Eng., vol. 165, pp. 59-69, Jan. 2018.

[22] G. Marques and R. Pitarma, "Non-contact Infrared Temperature Acquisition System based on Internet of Things for Laboratory Activities Monitoring," Procedia Comput. Sci., vol. 155, pp. 487494, 2019.

[23] Z. Zhang, H. Zhang, and T. Liu, "Study on body temperature detection of pig based on infrared technology: A review," Artif. Intell. Agric., vol. 1, pp. 14-26, Mar. 2019.

[24] K. Drechsler, I. Kisekka, and S. Upadhyaya, "A comprehensive stress indicator for evaluating plant water status in almond trees," Agric. Water Manag., vol. 216, no. February, pp. 214-223, May 2019.

[25] A. C. Cosma and R. Simha, "Thermal comfort modeling in transient conditions using real-time local body temperature extraction with a thermographic camera," Build. Environ., vol. 143, no. April, pp. 3647, Oct. 2018.

[26] R. Cortez-Vega, I. Chairez, A. Luviano-Juárez, and V. Feliu-Batlle, "A hybrid dynamic model of shape memory alloy spring actuators," Measurement, vol. 114, no. February 2017, pp. 340-353, Jan. 2018.

[27] J. Y. Kim and D. M. Glenn, "Multi-modal sensor system for plant water stress assessment," Comput. Electron. Agric., vol. 141, pp. 27-34, Sep. 2017.

[28] S. Crisan and B. Tebrean, "Low cost, high quality vein pattern recognition device with liveness Detection. Workflow and implementations," Meas. J. Int. Meas. Confed., vol. 108, pp. 207216, 2017.

[29] S. M. Torres Delgado, J. G. Korvink, and D. Mager, "The eLoaD platform endows centrifugal microfluidics with on-disc power and communication," Biosens. Bioelectron., vol. 117, no. April, pp. 464-473, Oct. 2018.

[30] J. Jiang and C. Claudel, "A high performance, low power computational platform for complex sensing operations in smart cities," HardwareX, vol. 1, pp. 22-37, Apr. 2017.

[31] A. McConville, J. Atchison, A. Roddy, and J. Davis, "A wireless smart patch for the controlled repetitive transdermal administration of therapeutic agents," Sensors Actuators B Chem., vol. 294, no. May, pp. 24-31, Sep. 2019.

[32] G. Aiello, I. Giovino, M. Vallone, P. Catania, and A. Argento, “A decision support system based on multisensor data fusion for sustainable greenhouse management," J. Clean. Prod., vol. 172, pp. 4057-4065, Jan. 2018. 